\title{
WRF Simulations of Extreme Rainfall over Uganda's Lake Victoria Basin: Sensitivity to Parameterization, Model Resolution and Domain Size
}

\author{
Ronald Opio ${ }^{*}$, Geoffrey Sabiiti²\#, Alex Nimusiima2\#, Isaac Mugume², Julianne Sansa-Otim³ \\ ${ }^{1}$ Department of Environmental Management, Makerere University, Kampala, Uganda \\ ${ }^{2}$ Department of Geography, Geoinformatics and Climatic Sciences, Makerere University, Kampala, Uganda \\ ${ }^{3}$ School of Computing and Information Technology, Makerere University, Kampala, Uganda \\ Email: ^opioronald123@gmail.com
}

How to cite this paper: Opio, R., Sabiiti, G., Nimusiima, A., Mugume, I., \& Sansa-Otim, J. (2020). WRF Simulations of Extreme Rainfall over Uganda's Lake Victoria Basin: Sensitivity to Parameterization, Model Resolution and Domain Size. Journal of Geoscience and Environment Protection, 8, 18-31. https://doi.org/10.4236/gep.2020.84002

Received: October 26, 2019

Accepted: April 10, 2020

Published: April 13, 2020

Copyright $\odot 2020$ by author(s) and Scientific Research Publishing Inc. This work is licensed under the Creative Commons Attribution International License (CC BY 4.0).

http://creativecommons.org/licenses/by/4.0/

\begin{abstract}
Rainfall extremes have strong connotations to socio-economic activities and human well-being in Uganda's Lake Victoria Basin (LVB). Reliable prediction and dissemination of extreme rainfall events are therefore of paramount importance to the region's development agenda. The main objective of this study was to contribute to the prediction of rainfall extremes over this region using a numerical modelling approach. The Weather Research and Forecasting (WRF) model was used to simulate a 20 -day period of extremely heavy rainfall that was observed in the March to May season of 2008. The underlying interest was to investigate the performance of different combinations of cumulus and microphysical parameterization along with the model grid resolution and domain size. The model output was validated against rainfall observations from the Tropical Rainfall Measuring Mission (TRMM) using 5 metrics; the rainfall distribution, root mean square error, mean error, probability of detection and false alarm ratio. The results showed that the model was able to simulate extreme rainfall and the most satisfactory skill was obtained with a model setup using the Grell 3D cumulus scheme combined with the SBU_YLin microphysical scheme. This study concludes that the WRF model can be used for simulating extreme rainfall over western LVB. In the other 2 regions, central and eastern LVB, its performance is limited by failure to simulate nocturnal rainfall. Furthermore, increasing the model grid resolution showed good potential for improving the model simulation especially when a large domain is used.
\end{abstract}

\#These authors made equal contribution to the work. 


\section{Keywords}

Extreme Rainfall, WRF, Parameterization, Model Resolution, Domain Size

\section{Introduction}

Rainfall is one of the important weather elements and its forecasting is crucial to society (Gouda et al., 2018; Mehr et al., 2019). In Uganda, occurrence of rainfall extremes has been associated with a variety of negative socio-economic impacts on human livelihood. For example, extremely heavy rainfall plays a principal role in soil erosion (Bamutaze et al., 2017), flooding (Lwasa, 2010), landslides (Mugagga et al., 2012) and transmission of waterborne diseases (Cann et al., 2013). Consequently, it causes substantial loss in rain-dependent sectors such as agriculture, public health, transport and disaster management among many others.

One direct way to tackle this problem of extreme rainfall is to use numerical weather prediction (NWP) models to forecast its occurrence. For this, the Uganda National Meteorological Authority has integrated NWP modelling in their weather forecasting service to support the generation of short and medium range forecasts and their model of choice is the Weather Research and Forecasting (WRF) model. This model's user community is on the rise signifying the confidence that scientists have in it (Warner, 2011). Also, it can be easily set-up for operational use since its outputs can be autonomously analyzed using existing state-of-the-science tools such as the Atmospheric Model Evaluation Tool (Appel et al., 2011).

As a major action, it is important to customize the WRF model over different regions of the country. This work focused on the Lake Victoria Basin (LVB) in Uganda (Figure 1(a)). Climatological zones in this region have been documented to receive substantially heavy rainfall (Majaliwa et al., 2015), therefore it seemed logical to explore the rainfall records of this region in the quest for extremely heavy rainfall. For this, the spatial rainfall anomaly for the longest rainfall season, March to May (MAM) was calculated based on TRMM rainfall for 20 years, 1998 to 2017. The analysis revealed the MAM season of 2008 as one which experienced extremely wet conditions over the land area (Figure 1(b)). The WRF model was then used to simulate a 20-day period ( $17^{\text {th }}$ March 2008 to $5^{\text {th }}$ April 2008) of extremely heavy rainfall identified within this season.

The aspects of the customization done in this work include: 1) identifying combinations of cumulus and microphysical parameterization that generate skillful simulations of extreme rainfall over the region; 2) determining the sensitivity of the simulations to increasing the model resolution and changing the domain size. This work used 2 independent domain set-ups (Table 1).

\section{Data and Methods}

\subsection{Data}

\section{Boundary conditions}

The WRF model simulations were initialized using Final Operational Model 


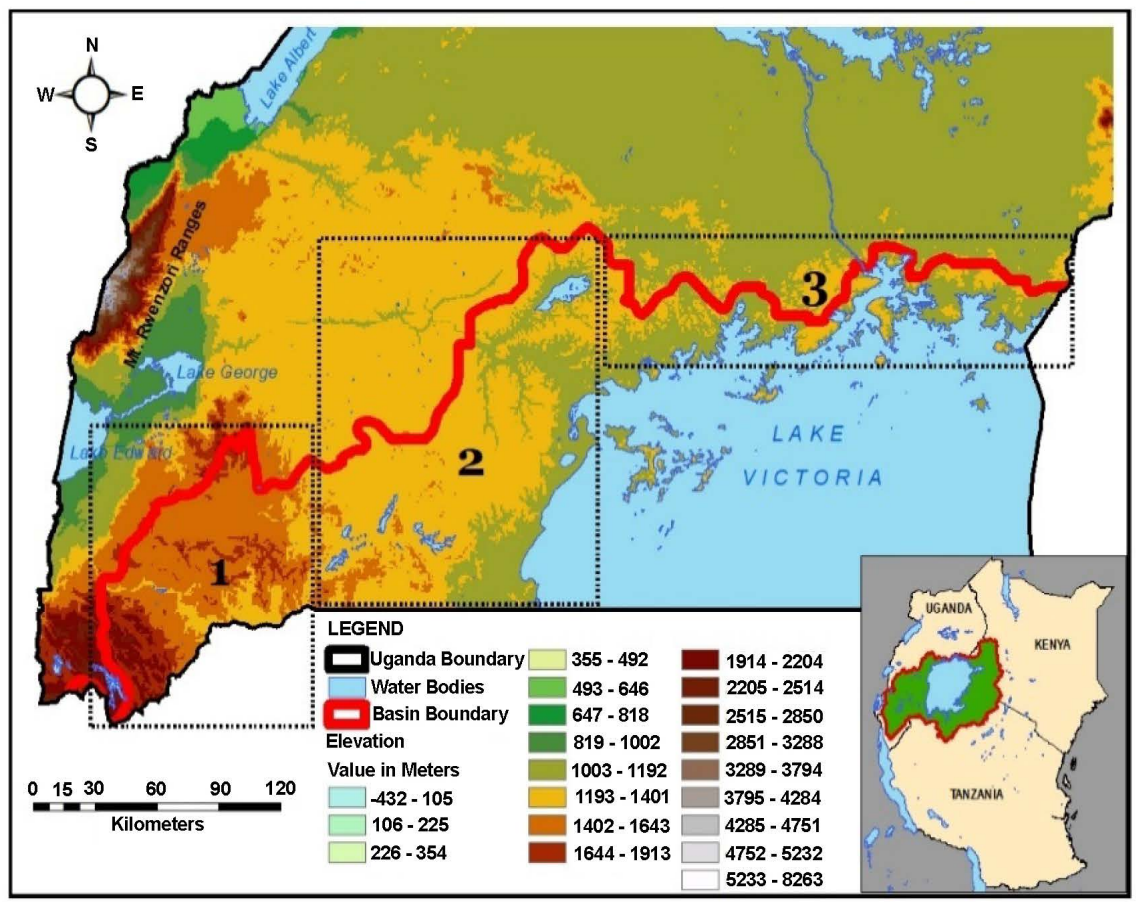

(a)

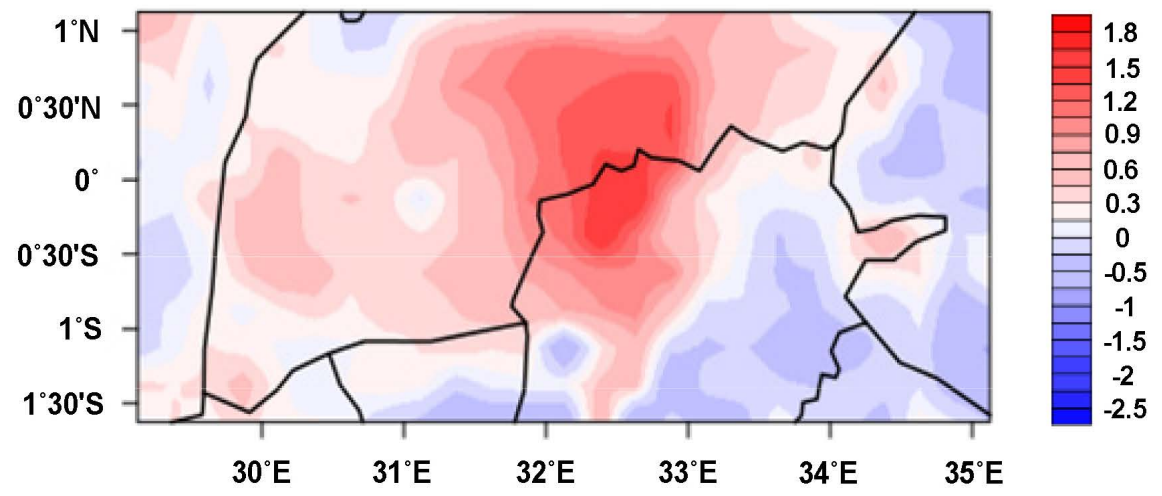

(b)

Figure 1. (a) Map of the Lake Victoria Basin in Uganda. The dotted rectangles are the representative regions of the basin. Region 1 is western LVB, region 2 is central LVB and region 3 is eastern LVB. (b) Spatial rainfall anomaly $(\mathrm{mm})$ for March to May, 2008 based on TRMM rainfall for 20 years, 1998 to 2017.

Table 1. Domain setup for WRF model experiments.

\begin{tabular}{ccc}
\hline Domain/Set-up & Set-up 1 & Set-up 2 \\
\hline Coarse & $\begin{array}{c}108 \mathrm{~km} \text { spacing } \\
(84 \times 84 \text { grids })\end{array}$ & $36 \mathrm{~km}$ spacing \\
& & $(250 \times 250$ grids $)$ \\
$\mathrm{d} 02$ & $36 \mathrm{~km}$ spacing & $12 \mathrm{~km}$ spacing \\
& $(163 \times 73$ grids $)$ & $(490 \times 220$ grids $)$ \\
$\mathrm{d} 03$ & $12 \mathrm{~km}$ spacing & $4 \mathrm{~km}$ spacing \\
& $(67 \times 52$ grids $)$ & $(202 \times 151$ grids $)$ \\
\end{tabular}


Global Tropospheric Reanalyzes from the National Center for Environmental Prediction (NCEP FNL). This is 6-hourly data of $1^{\circ} \times 1^{\circ}(110 \mathrm{~km})$ resolution (Kalnay et al., 1996). The boundary conditions used were for 21 days, corresponding to the study period of 20 days with an additional day to cater for model spin-up.

\section{Rainfall observations}

The Tropical Rainfall Measuring Mission (TRMM) provided observations for model validation. Observed estimates of daily and 3-hourly rainfall accumulations were obtained from TRMM $3 \mathrm{~B} 42$ version 7 . This product is a $0.25^{\circ} \times 0.25^{\circ}$ $(27.5 \mathrm{~km})$ resolution precipitation estimate obtained by applying the Goddard Profiling Algorithm to extract rainfall estimates from a variety of passive microwave sources (Huffman et al., 2007). The dataset was downloaded from the GIOVANNI data handle (https://giovanni.gsfc.nasa.gov/giovanni/) of the National Aeronautics and Space Administration (NASA). Data for a 20-day period was used for evaluating the model performance.

\subsection{Methods}

\section{Model setup and experimental design}

Simulation of extreme rainfall that occurred over the LVB was done using the WRF modelling system, Advanced Research WRF (ARW) core version 3.9. It is a grid point model with a terrain-following vertical coordinate near the surface which transforms to a constant pressure at the highest level. WRF performs numerical integration on a staggered Arakawa C-grid with $3^{\text {rd }}$ order Runge-Kutta time integration (Skamarock et al., 2008). The model was setup with 27 vertical levels ending at the $50 \mathrm{hPa}$ isobaric level. Three domains (Table 1 and Figure 2) of varying grid resolution were used with a superior 2-way domain interaction and 1:3 nesting ratio. The model was initialized using NCEP finalized reanalyzes starting 24 hours before the period of interest to allow time for model spin-up.

The domain setup was as follows; a coarse domain centered at $0.73^{\circ}$ latitude, $22^{\circ}$ longitude covering Africa to encompass large scale synoptic systems such as the Inter Tropical Convergence Zone and sub-tropical anti-cyclones; a nest domain $\mathrm{d} 02$, covering the Congo basin and the western region of the Indian Ocean to cater for moisture inflow from the Congo air mass and the Indian Ocean respectively; and a nest domain d03, covering LVB and Lake Victoria to cater for the influence of lake surface temperatures on rainfall in the basin. The ARW solver was used with a combination of physical parameterization (Table 2) coupled with static land-use data based on Moderate Resolution Imaging Spectroradiometer (MODIS) with 21 land-use categories (Friedl et al., 2002) and a special lake surface representation. The land-use was setup with varying resolution, the coarse domain used a 10-minute resolution while $\mathrm{d} 02$ and $\mathrm{d} 03$ used a 5 -minute resolution.

To determine the model skill associated with the use of different cumulus microphysical scheme combinations, the model setup was identical in all experiments, except for the cumulus and microphysical schemes (Table 2). Similar to Argent et al. (2015), the default parameterization settings of the WRF model were used as the control run. 


\section{WPS Domain Configuration}

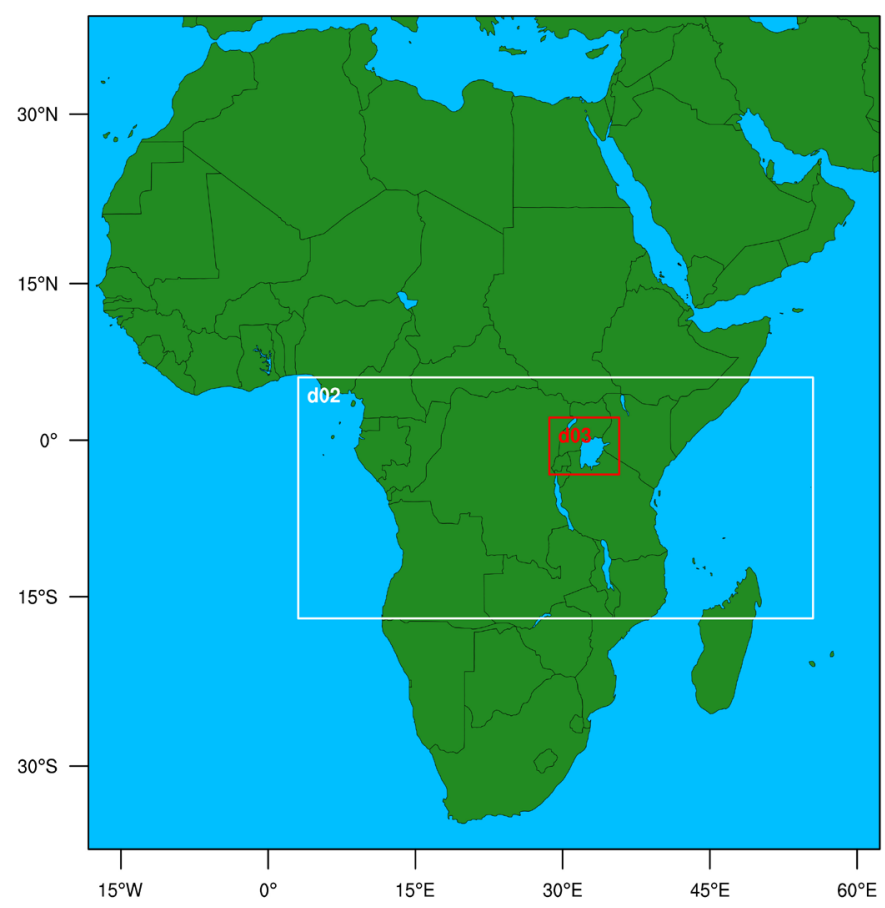

Figure 2. Domain configuration for WRF simulations.

Table 2. WRF model physical setup.

\begin{tabular}{|c|c|c|c|c|c|c|c|}
\hline Experiment & $\begin{array}{l}\text { Cumulus } \\
\text { Scheme }\end{array}$ & Microphysics scheme & PBL scheme & $\begin{array}{c}\text { Radiation } \\
\text { (short-wave) }\end{array}$ & $\begin{array}{l}\text { Radiation } \\
\text { (long wave) }\end{array}$ & $\begin{array}{c}\text { Land surface } \\
\text { model }\end{array}$ & $\begin{array}{l}\text { Surface } \\
\text { scheme }\end{array}$ \\
\hline Control run & $\mathrm{KF}$ & WSM3 & YSU & Dudhia & RRTM & NOAH & MM5 \\
\hline E1 & GF & Eta & YSU & Dudhia & RRTM & $\mathrm{NOAH}$ & MM5 \\
\hline E2 & GF & Milbrandt & YSU & Dudhia & RRTM & NOAH & MM5 \\
\hline E3 & GF & SBU_YLin & YSU & Dudhia & RRTM & NOAH & MM5 \\
\hline E4 & Grell 3D & Eta & YSU & Dudhia & RRTM & $\mathrm{NOAH}$ & MM5 \\
\hline E5 & Grell 3D & Milbrandt & YSU & Dudhia & RRTM & NOAH & MM5 \\
\hline E6 & Grell 3D & SBU_YLin & YSU & Dudhia & RRTM & $\mathrm{NOAH}$ & MM5 \\
\hline E7 & BMJ & Eta & YSU & Dudhia & RRTM & NOAH & MM5 \\
\hline E8 & BMJ & Milbrandt & YSU & Dudhia & RRTM & NOAH & MM5 \\
\hline E9 & BMJ & SBU_YLin & YSU & Dudhia & RRTM & NOAH & MM5 \\
\hline
\end{tabular}

To determine the effect of changing grid resolution, experiments done in set-up 1 were repeated with the inner most domain set to $4 \mathrm{~km}$ resolution (Set-up 2). A comparison was then done between results of experiments at $12 \mathrm{~km}$ resolution and experiments at $4 \mathrm{~km}$ resolution. Furthermore, to reveal the effect of changing domain size, a comparison was done between results of domain, d03 in set-up 1 and domain, d02 in set-up 2. Both domains were set at $12 \mathrm{~km}$ resolution and only differed in size. 


\section{Model validation methods}

The Difference variable. (Willmott et al., 1985) described in Equation (1) was used to generate a spatial difference between the WRF output and TRMM.

$$
\text { Difference }=\text { Simulated }- \text { Observed }
$$

Continuous scores. The Root Mean Square Error (RMSE) (Chai \& Draxler, $2014)$ was used to determine model accuracy, and the Mean Error $(M E)(\mathrm{Mu}-$ gume et al., 2016) was used to determine model bias.

$$
\begin{aligned}
\text { RMSE } & =\sqrt{\frac{1}{n} \sum_{i=1}^{n}\left(S_{i}-O_{i}\right)^{2}} \\
M E & =\frac{1}{n} \sum_{i=1}^{n}\left(S_{i}-O_{i}\right)
\end{aligned}
$$

In Equations (2) and (3), $S$ is the simulated value, $O$ is the observed value, and $n$ is the total number of comparisons.

Categorical scores. The scores used were the Probability of Detection (POD) and False Alarm Ratio (FAR) described in Equations (4) and (5) respectively. POD and FAR values range from 0 to 1 and they are derived from a $2 \times 2$ contingency table (Table 3) described by Schaefer (1990).

Table $3.2 \times 2$ contingency table.

\begin{tabular}{ccc}
\hline Observations/WRF & Yes & No \\
\hline Yes & Hit (A) & Miss (C) \\
No & False Alarm (B) & Correct Negative (D) \\
\hline & $P O D=A /(A+C)$ & \\
& $F A R=B /(A+B)$ &
\end{tabular}

\section{Results and Discussion}

\subsection{WRF Simulations of Extreme Rainfall under Different Parameterization Settings}

\section{Observed and simulated spatial rainfall patterns}

Figure 3 shows the rainfall distribution from TRMM observations and the WRF model runs for the 20-day period. TRMM shows that the total rainfall amount received in LVB during this period was between 100 and $280 \mathrm{~mm}$ although rainfall amounts between 120 to $200 \mathrm{~mm}$ dominated the area and central LVB received a higher rainfall amount compared to the other 2 regions. On the contrary, all model runs generated higher rainfall amounts in the higher altitude western LVB compared to the other 2 regions. This gives evidence of the terrain-sensitive nature of the WRF model which was also reported by Mugume et al. (2017) and Ntwali et al. (2016).

The model runs also generated varying rainfall distributions when different cumulus and microphysical parameterization combinations were used. Overall, the rainfall was in the range of 10 to over $320 \mathrm{~mm}$. Notably, runs done with the SBU_YLin microphysical scheme (Figure 3(e), Figure 3(h), \& Figure 3(k)) 

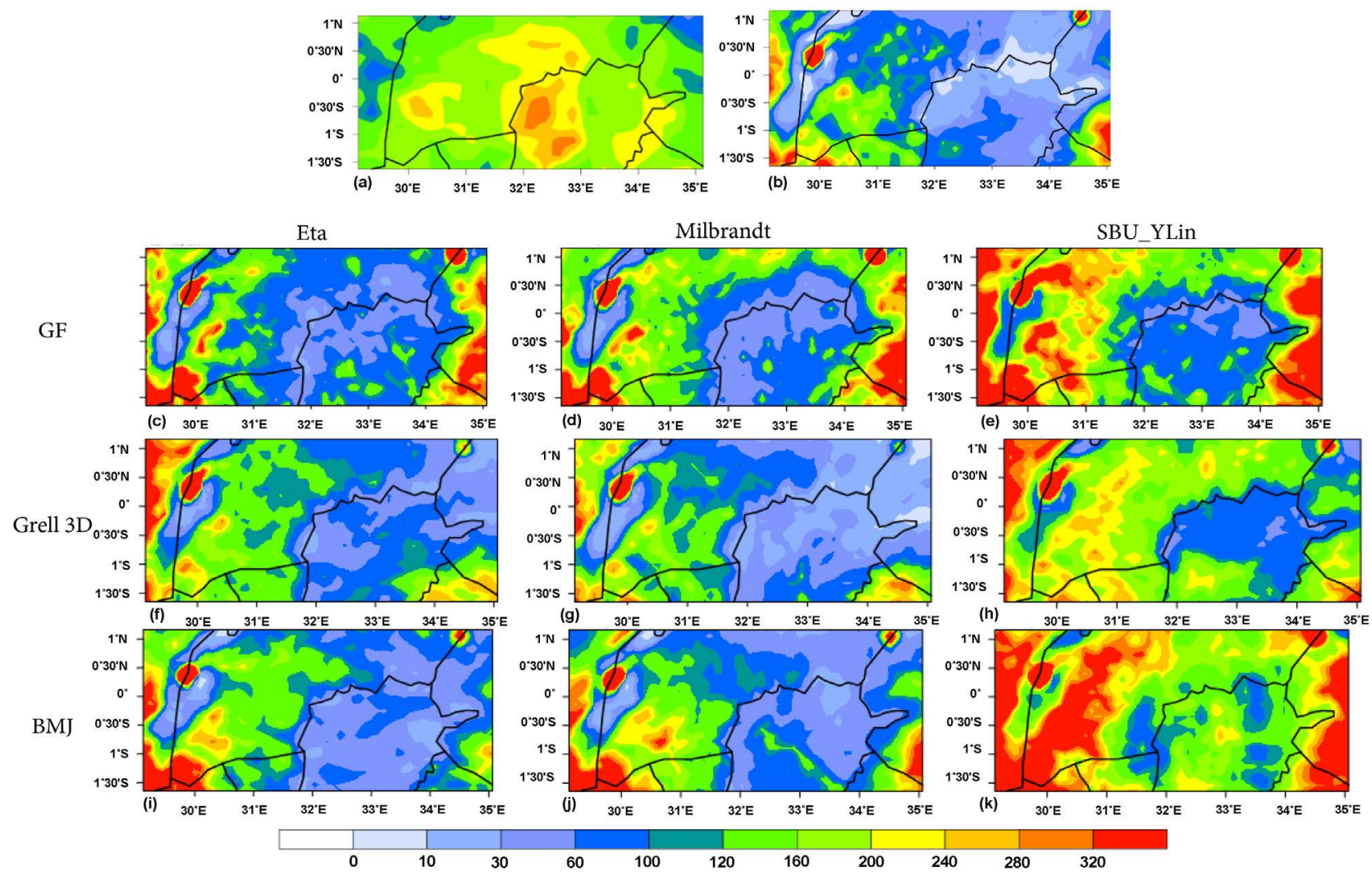

Figure 3. Total rainfall amount ( $\mathrm{mm}$ ) from TRMM data (a), the control run (b) and experimental runs E1 to E9 (c to k). The plots $\mathrm{c}$ to $\mathrm{k}$ are also arranged following the cumulus schemes (rows) and microphysical schemes (columns) used.

generated higher rainfall amounts over LVB as compared to those done with other microphysical schemes. This rainfall disparity caused by the microphysical scheme is because they each use different techniques for predicting hydrometeor species.

The difference maps (Figure 4) show that all model runs underestimated the rainfall in the watershed closet to the lake. Also, except for the runs done with the Grell 3D cumulus scheme, the other runs overestimated rainfall in the highland areas in the southwestern corner of the basin. Of the areas in which the model runs show close agreement, the error ranged from 25 to $50 \mathrm{~mm}$ and very few areas had an error below $25 \mathrm{~mm}$.

\section{Observed and simulated temporal rainfall patterns}

Figure 5 shows the temporal rainfall accumulation (a, c, e) and the diurnal evolution of rainfall $(b, d, f)$ during the 20-day period for western, central and eastern LVB respectively. The temporal rainfall accumulation indicates that for western LVB, the model runs fairly simulate the rainfall amounts while for central and eastern LVB, there was a dominant underestimation of the rainfall. A further investigation into the diurnal variation (Figure 5(b), Figure 5(d), Figure 5(f)) alludes that the underestimation happens during the nocturnal hours of the day. For central LVB, the model, this is between 18:00 hrs. to 06:00 hrs. of the following day while for eastern LVB, this happens between 18:00 hrs. and 24:00 hrs. 

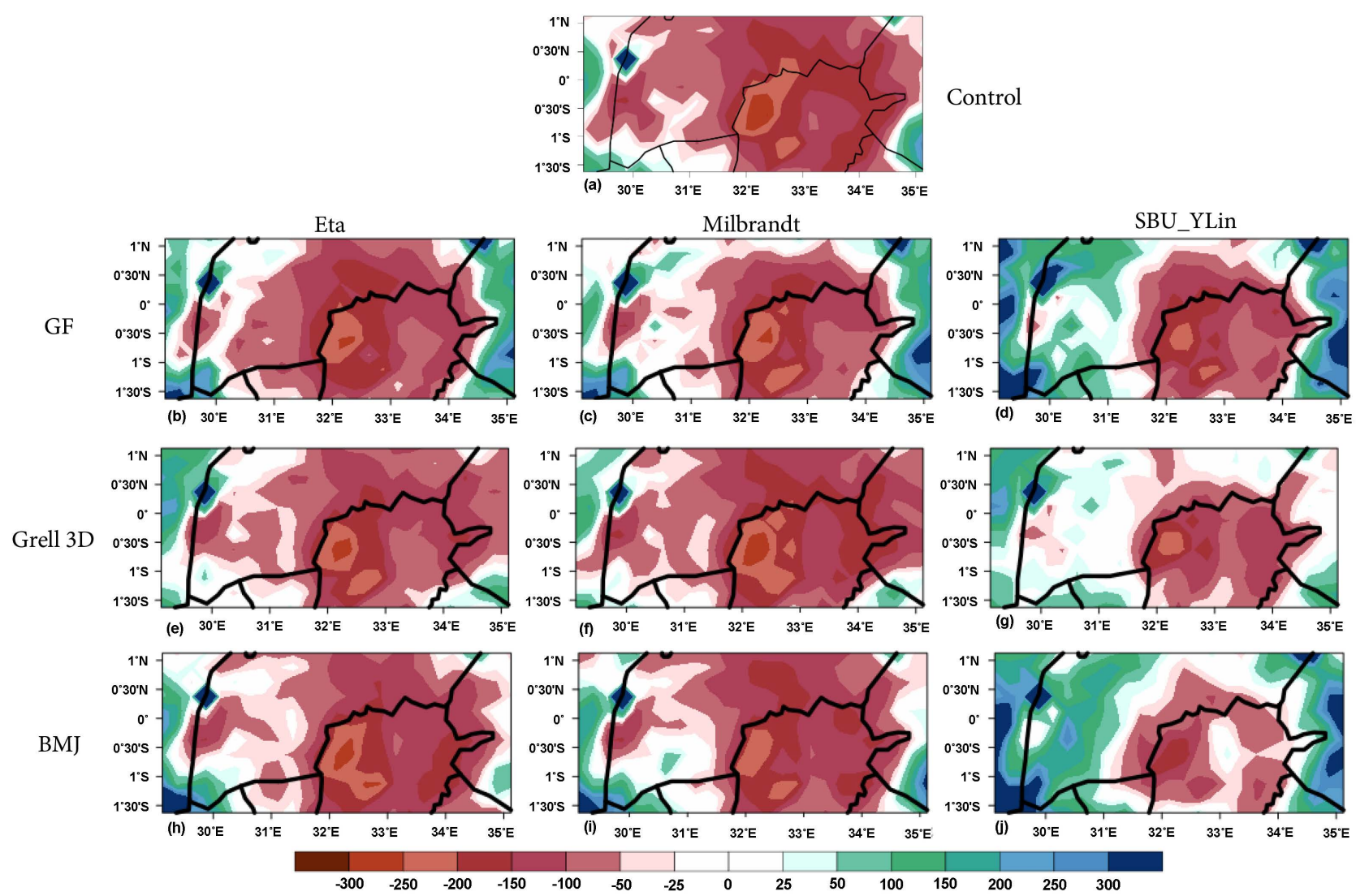

Figure 4. Difference in total rainfall amount $(\mathrm{mm})$ between WRF model output and TRMM data for the 20-day period.

Important to note is that TRMM observations $(\mathrm{b}, \mathrm{d}, \mathrm{f})$ show that rainfall in the basin is mostly received at night and early in the morning. Sun et al. (2014) demonstrated that during this time, the lake is warmer than the adjacent land, favoring the occurrence of a land breeze that causes the rainfall. The WRF model, however, was unable to correctly simulate this nocturnal rainfall caused by the land breeze. As explained by Argent et al. (2015), there is insufficiency in the representation of the lake surface temperature within the model. The temperature of the lake is constantly colder than the adjacent land. This hinders the reversal of winds to blow from the land to the lake (that is, failure to generate the land breeze). The lack of nocturnal rainfall also explains why the model underestimated rainfall in central and eastern LVB. Mayor and Mesquita (2015) also acknowledged a similar failure of WRF over Cuba.

\section{Skill scores}

Table 4 summarizes the skill scores and corresponding ranks of model runs done using an inner-most domain set at $12 \mathrm{~km}$ resolution (Set-up 1). A one-sample $t$-test was used to test whether the skill scores generated by model runs E1 to E9 significantly differ from those of the control run and the results show that at a 95\% level of confidence, changing the microphysical and cumulus parameterization schemes from the default significantly altered the model bias (ME, $p<0.05$ ), detection ability (POD, $p<0.05$ ) and proportion of false alarms (FAR, $p<0.05$ ) 


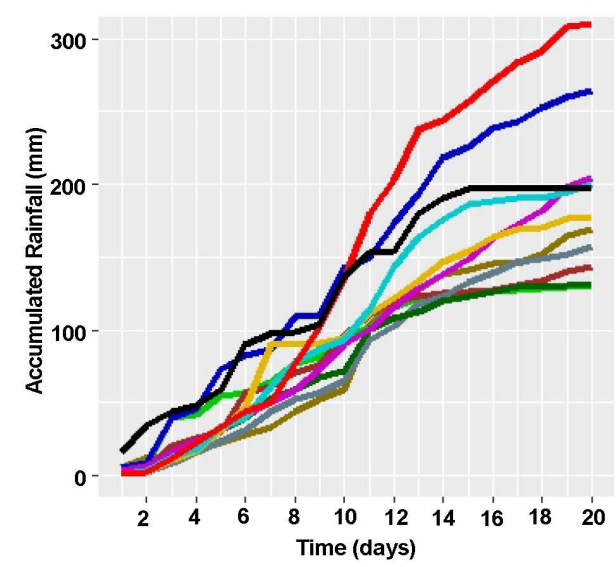

(a)

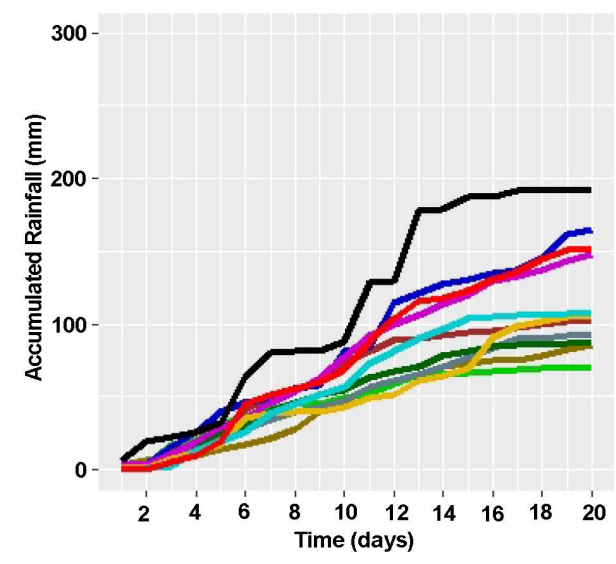

(c)

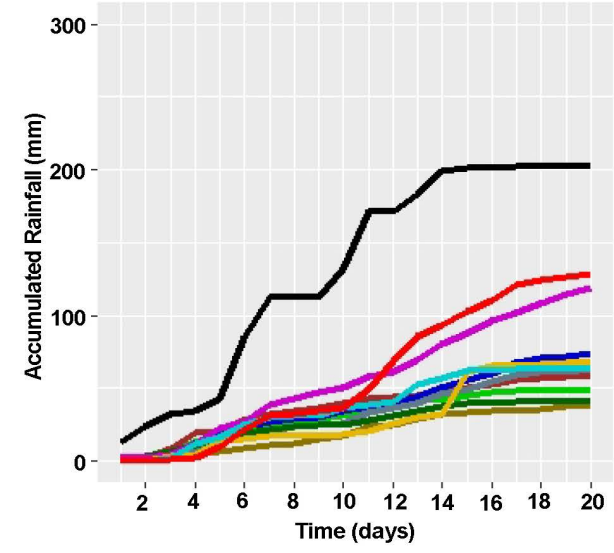

(e)

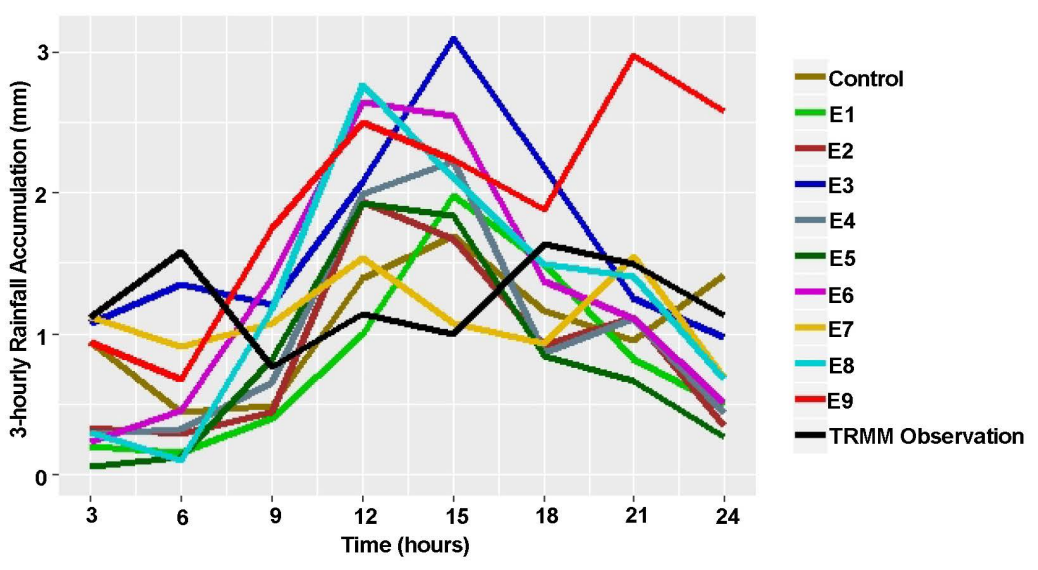

(b)
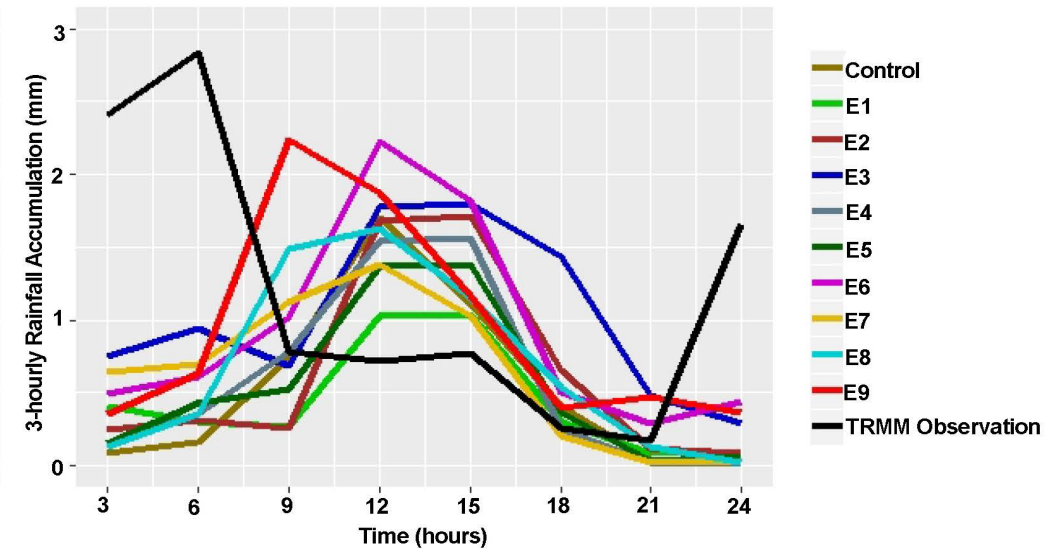

(d)
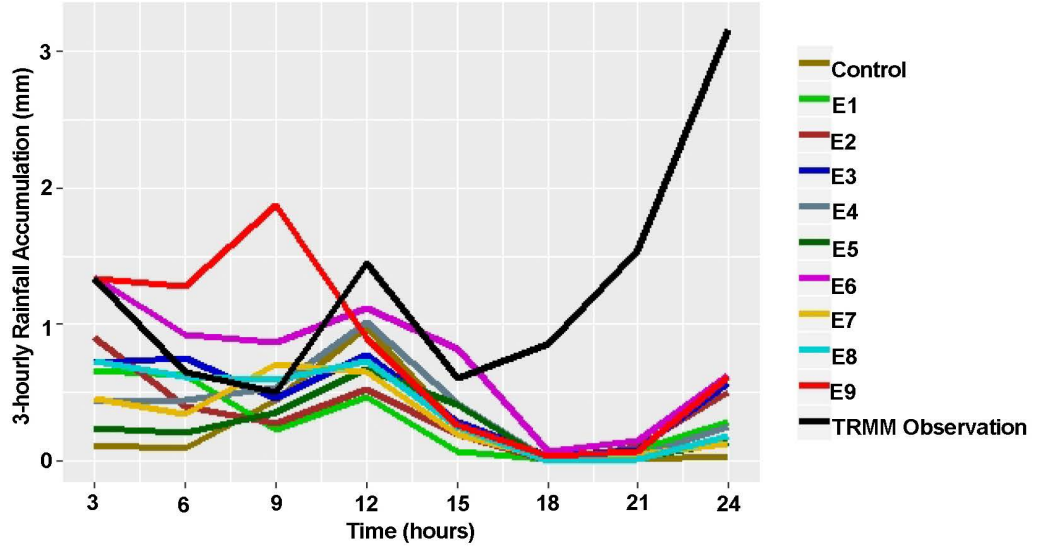

(f)

Figure 5. Temporal rainfall accumulation ( $\mathrm{mm}$ ) for the 20-day period (left column) and 3-hourly rainfall accumulation (mm) (right column) for western LVB (a), (b), central LVB (c), (d) and eastern LVB (e), (f).

but not the accuracy (RMSE, $p>0.05$ ). Overall, model runs done with the Grell 3D cumulus scheme showed closer proximity to the TRMM observations and specifically, model run E6 done with the Grell 3D cumulus scheme combined with the SBU_YLin microphysical scheme showed the most satisfactory skill and generated the best spatial representation of the rainfall. 
Table 4. Ranks of the model skill scores for runs done at $12 \mathrm{~km}$ resolution.

\begin{tabular}{ccccccccc}
\hline Experiment & RMSE & ME (mm) & POD & FAR & $\begin{array}{c}\text { RMSE } \\
\text { Rank }\end{array}$ & $\begin{array}{c}\text { ME } \\
\text { Rank }\end{array}$ & $\begin{array}{c}\text { POD } \\
\text { Rank }\end{array}$ & $\begin{array}{c}\text { FAR } \\
\text { Rank }\end{array}$ \\
\hline Control run & 137.21 & -60.18 & 0.86 & 0.39 & 4 & 8 & 10 & 3.5 \\
E1 & 141.85 & -32.53 & 0.94 & 0.39 & 5 & 4 & 6.5 & 3.5 \\
E2 & 150.98 & -16.81 & 1 & 0.40 & 8 & 2 & 1.5 & 6 \\
E3 & 192.81 & 47.34 & 0.99 & 0.41 & 9 & 6 & 3 & 8.5 \\
E4 & 117.77 & -57.43 & 1 & 0.41 & 2 & 7 & 1.5 & 8.5 \\
E5 & 125.60 & -82.79 & 0.97 & 0.38 & 3 & 9 & 5 & 1 \\
E6 & 109.26 & -15.71 & 0.98 & 0.41 & 1 & 1 & 4 & 8.5 \\
E7 & 144.12 & -36.13 & 0.91 & 0.39 & 6 & 5 & 9 & 3.5 \\
E8 & 147.36 & -26.51 & 0.94 & 0.39 & 7 & 3 & 6.5 & 3.5 \\
E9 & 225.75 & 99.09 & 0.92 & 0.41 & 10 & 10 & 8 & 8.5 \\
\hline
\end{tabular}

\subsection{Effect of Grid Resolution on WRF Model Skill in Simulating Extreme Rainfall}

\section{Effect of model resolution on the skill scores}

The 10 model runs done with the inner most domain set to $12 \mathrm{~km}$ (Set-up 1) were repeated with the inner most domain set to $4 \mathrm{~km}$ (Set-up 2) and the skill scores they generated were summarized in Table 5 along with the corresponding ranks. Model runs E4 and E6 which both use the Grell 3D cumulus scheme rank higher than the rest of the model runs.

Furthermore, the skill scores of the model runs at both resolutions were summarized in Table 6 and a paired-sample t-test was used to test the effect that changing model resolution from $12 \mathrm{~km}$ to $4 \mathrm{~km}$ has on the model skill. The results show that it significantly affected the accuracy (RMSE, $p<0.05$ ), detection ability (POD, $p<0.05$ ) and proportion of false alarms (FAR, $p<0.05)$ but did not significantly alter the model bias (ME, $p>0.05$ ). Majority of the model runs generated lower RMSE, lower POD and higher FAR at $4 \mathrm{~km}$ resolution compared to the $12 \mathrm{~km}$ resolution. This implies that increasing the model's resolution produced a higher accuracy, lowered the detection ability by $2 \%$ or more and increased the number of false alarms by $1 \%$ to $2 \%$. For the Control run, E1, E2, E7 and E8, increasing the model resolution was of no additional value. It caused an undesirable increase in model bias.

\section{Effect of domain size on the skill scores}

The nature of the experimental set-up allowed for a domain-size sensitivity test to be carried out. For this, the paired-sample t-test was used to compare the skill scores generated by domain, d03 set at $12 \mathrm{~km}$ resolution (Set-up 1) to those of domain, d02 also set at $12 \mathrm{~km}$ resolution (Set-up 2). These domains only differed in size. The results (Table 7) suggest that changing the size of the domain significantly altered the model's accuracy (RMSE, $p<0.05$ ) and proportion of false alarms (FAR, $p<0.05$ ). Majority of the model runs generated lower RMSE in the large domain. This increase in accuracy is because synoptic features are 
Table 5. Ranks of the model skill scores for runs done at $4 \mathrm{~km}$ resolution.

\begin{tabular}{ccccccccc}
\hline Experiment & RMSE & $\begin{array}{c}\text { ME } \\
(\mathrm{mm})\end{array}$ & POD & FAR & $\begin{array}{c}\text { RMSE } \\
\text { Rank }\end{array}$ & $\begin{array}{c}\text { ME } \\
\text { Rank }\end{array}$ & $\begin{array}{c}\text { POD } \\
\text { Rank }\end{array}$ & $\begin{array}{c}\text { FAR } \\
\text { Rank }\end{array}$ \\
\hline Control run & 126.40 & -86.93 & 0.82 & 0.41 & 8 & 10 & 10 & 4.5 \\
E1 & 120.46 & -86.43 & 0.87 & 0.39 & 6 & 9 & 9 & 1.5 \\
E2 & 104.42 & -23.99 & 0.95 & 0.42 & 2 & 3 & 4 & 8.5 \\
E3 & 129.57 & -0.51 & 0.96 & 0.42 & 9 & 1 & 2.5 & 8.5 \\
E4 & 100.64 & -29.88 & 0.94 & 0.42 & 1 & 4 & 5.5 & 8.5 \\
E5 & 108.77 & -64.34 & 0.97 & 0.39 & 3 & 6 & 1 & 1.5 \\
E6 & 113.39 & 3.24 & 0.96 & 0.41 & 4 & 2 & 2.5 & 4.5 \\
E7 & 114.19 & -42.47 & 0.93 & 0.41 & 5 & 5 & 7.5 & 4.5 \\
E8 & 123.90 & -69.86 & 0.93 & 0.41 & 7 & 8 & 7.5 & 4.5 \\
E9 & 162.53 & 69.08 & 0.94 & 0.42 & 10 & 7 & 5.5 & 8.5 \\
\hline
\end{tabular}

Table 6. Skill scores generated by the $12 \mathrm{~km}$ and $4 \mathrm{~km}$ model runs.

\begin{tabular}{ccccccccc}
\hline Experiment & $\mathrm{RMSE}_{12}$ & $\mathrm{ME}_{12}$ & $\mathrm{POD}_{12}$ & $\mathrm{FAR}_{12}$ & $\mathrm{RMSE}_{4}$ & $\mathrm{ME}_{4}$ & $\mathrm{POD}_{4}$ & $\mathrm{FAR}_{4}$ \\
\hline Control run & 137.21 & -60.18 & 0.86 & 0.39 & 126.40 & -86.93 & 0.82 & 0.41 \\
E1 & 141.85 & -32.53 & 0.94 & 0.39 & 120.46 & -86.43 & 0.87 & 0.39 \\
E2 & 150.98 & -16.81 & 1 & 0.40 & 104.42 & -23.99 & 0.95 & 0.42 \\
E3 & 192.81 & 47.34 & 0.99 & 0.41 & 129.57 & -0.51 & 0.96 & 0.42 \\
E4 & 117.77 & -57.43 & 1 & 0.41 & 100.64 & -29.88 & 0.94 & 0.42 \\
E5 & 125.60 & -82.79 & 0.97 & 0.38 & 108.77 & -64.34 & 0.97 & 0.39 \\
E6 & 109.26 & -15.71 & 0.98 & 0.41 & 113.39 & 3.24 & 0.96 & 0.41 \\
E7 & 144.12 & -36.13 & 0.91 & 0.39 & 114.19 & -42.47 & 0.93 & 0.41 \\
E8 & 147.36 & -26.51 & 0.94 & 0.39 & 123.90 & -69.86 & 0.93 & 0.41 \\
E9 & 225.75 & 99.09 & 0.92 & 0.41 & 162.53 & 69.08 & 0.94 & 0.42 \\
\hline
\end{tabular}

Table 7. Skill scores generated by model runs when different domain sizes of the same resolution are used. The subscripts $S$ and $L$ denote small and large domain respectively.

\begin{tabular}{ccccccccc}
\hline Experiment & RMSEs & MEs & PODs & FARs & RMSEL & MEL & PODL & FARL \\
\hline Control run & 137.21 & -60.18 & 0.86 & 0.39 & 127.05 & -83.74 & 0.94 & 0.40 \\
E1 & 141.85 & -32.53 & 0.94 & 0.39 & 120.34 & -82.51 & 0.92 & 0.40 \\
E2 & 150.98 & -16.81 & 1 & 0.40 & 107.97 & -19.32 & 0.98 & 0.41 \\
E3 & 192.81 & 47.34 & 0.99 & 0.41 & 138.33 & 5.42 & 0.99 & 0.41 \\
E4 & 117.77 & -57.43 & 1 & 0.41 & 104.88 & -25.03 & 0.97 & 0.42 \\
E5 & 125.60 & -82.79 & 0.97 & 0.38 & 110.08 & -60.44 & 0.98 & 0.39 \\
E6 & 109.26 & -15.71 & 0.98 & 0.41 & 122.72 & 9.99 & 0.98 & 0.41 \\
E7 & 144.12 & -36.13 & 0.91 & 0.39 & 115.22 & -41.54 & 0.97 & 0.41 \\
E8 & 147.36 & -26.51 & 0.94 & 0.39 & 124.22 & -69.32 & 0.97 & 0.41 \\
E9 & 225.75 & 99.09 & 0.92 & 0.41 & 164.22 & 70.69 & 0.97 & 0.41 \\
\hline
\end{tabular}


better resolved in large domains. The large domain used in this test covered an approximate area of more than $15,000,000 \mathrm{~km}^{2}$, making it suitable to capture large scale features such as the ITCZ which is responsible for rainfall in LVB during the March to May season. However, the large domain was disadvantaged by its large spatial coverage because it registered a higher number of false alarms.

\section{Conclusion and Recommendations}

It is difficult to objectively identify the best parameterization combination because each combination ranked differently depending on the validation metric and the model resolution being considered. However, the Grell 3D cumulus scheme combined with the SBU_YLin microphysical scheme showed higher skill than the others and therefore can be considered as more appropriate for use in numerical simulations of extreme rainfall in equatorial regions.

The WRF model showed strong performance in western LVB. Overall bias was majorly contributed to by central and eastern LVB. The model's failure to simulate nocturnal rainfall in these 2 regions can hinder its capability to generate reliable forecasts of nocturnal thunderstorms. This can also affect its long-term simulations of the rainfall climatology over this region. Furthermore, the benefit of increasing the model grid resolution depends on the parameterization schemes used. In this study, it was mostly useful for experiments done with the Grell 3D cumulus scheme. Therefore, this scheme is suitable for high resolution numerical simulations of rainfall in equatorial regions. Also, there is added value in using a large domain in comparison to a small one.

\section{Acknowledgements}

This work was supported by the WIMEA-ICT project (https://wimea-ict.net/) with funding from the Norwegian Agency for Development Cooperation (NORAD). The NCEP FNL reanalysis data was obtained from the NCAR research data archive and the TRMM rainfall observations were obtained from the Giovanni data handle of NASA.

\section{Conflicts of Interest}

The authors declare no conflicts of interest regarding the publication of this paper.

\section{References}

Appel, K. W., Gilliam, R. C., Davis, N., Zubrow, A., Howard, S. C., Gilliam, D. R. C., Drive, A. T. W. A. et al. (2011). Overview of the Atmospheric Model Evaluation Tool (AMET) v1.1 for Evaluating Meteorological and Air Quality Models. Environmental Modelling and Software, 26, 434-443. https://doi.org/10.1016/j.envsoft.2010.09.007

Argent, R., Sun, X., Semazzi, F., Xie, L., \& Liu, B. (2015). The Development of a Customization Framework for the WRF Model over the Lake Victoria Basin, Eastern Africa on Seasonal Timescales. Advances in Meteorology, 2015, Article ID: 653473.

https://doi.org/10.1155/2015/653473 
Bamutaze, Y., Wanyama, J., Diekrugger, B., Meadows, M., \& Opedes, H. (2017). Dynamics of Surface Runoff and Soil Loss from a Toposequence under Varied Land Use Practices in Rwizi Catchment, Lake Victoria Basin. Journal of Soil and Water Conservation, 72, 480-492. https://doi.org/10.2489/jswc.72.5.480

Cann, K. F., Thomas, D. R., Salmon, R. L., Wyn-Jones, A. P., \& Kay, D. (2013). Extreme Water-Related Weather Events and Waterborne Disease. Epidemiology and Infection, 141, 671-686. https://doi.org/10.1017/S0950268812001653

Chai, T., \& Draxler, R. R. (2014). Root Mean Square Error (RMSE) or Mean Absolute Error (MAE)? Arguments against Avoiding RMSE in the Literature. Geoscientific Model Development, 7, 1247-1250. https://doi.org/10.5194/gmd-7-1247-2014

Friedl, M. A., McIver, D. K., Hodges, J. C. F., Zhang, X., Muchoney, D., Strahler, A. H., Schaaf, C. et al. (2002). Global Land Cover Mapping from MODIS: Algorithms and Early Results. Remote Sensing of Environment, 83, 287-302.

https://doi.org/10.1016/S0034-4257(02)00078-0

Gouda, K. C., Nahak, S., \& Goswami, P. (2018). Evaluation of a GCM in Seasonal Forecasting of Extreme Rainfall Events over Continental India. Weather and Climate EXtremes, 21, 10-16. https://doi.org/10.1016/j.wace.2018.05.001

Huffman, G. J., Bolvin, D. T., Nelkin, E. J., Wolff, D. B., Adler, R. F., Gu, G., Stocker, E. F. et al. (2007). The TRMM Multisatellite Precipitation Analysis (TMPA): Quasi-Global, Multiyear, Combined-Sensor Precipitation Estimates at Fine Scales. Journal of Hydrometeorology, 8, 38-55. https://doi.org/10.1175/JHM560.1

Kalnay, E., Kanamitsu, M., Kistler, R., Collins, W., Deaven, D., Gandin, L., Joseph, D. et al. (1996). The NCEP/NCAR 40-Year Reanalysis Project. Bulletin of the American Meteorological Society, 77, 437-471. https://doi.org/10.1175/1520-0477(1996)077<0437:TNYRP>2.0.CO;2

Lwasa, S. (2010). Adapting Urban Areas in Africa to Climate Change: The Case of Kampala. Current Opinion in Environmental Sustainability, 2, 166-171. https://doi.org/10.1016/j.cosust.2010.06.009

Majaliwa, J. G. M., Tenywa, M. M., Bamanya, D., Majugu, W., Isabirye, P., Nandozi, C., Sridher, G. et al. (2015). Characterization of Historical Seasonal and Annual Rainfall and Temperature Trends in Selected Climatological Homogenous Rainfall Zones of Uganda. Global Journal of Science Frontier Research, 15, 21-40.

Mayor, Y. G., \& Mesquita, M. D. S. (2015). Numerical Simulations of the 1 May 2012 Deep Convection Event over Cuba: Sensitivity to Cumulus and Microphysical Schemes in a High-Resolution Model. Advances in Meteorology, 2015, Article ID: 973151. https://doi.org/10.1155/2015/973151

Mehr, A. D., Nourani, V., Karimi Khosrowshahi, V., \& Ghorbani, M. A. (2019). A Hybrid Support Vector Regression-Firefly Model for Monthly Rainfall Forecasting. International Journal of Environmental Science and Technology, 16, 335-346.

https://doi.org/10.1007/s13762-018-1674-2

Mugagga, F., Kakembo, V., \& Buyinza, M. (2012). A Characterisation of the Physical Properties of Soil and the Implications for Landslide Occurrence on the Slopes of Mount Elgon, Eastern Uganda. Natural Hazards, 60, 1113-1131. https://doi.org/10.1007/s11069-011-9896-3

Mugume, I., Waiswa, D., Mesquita, M., Reuder, J., Basalirwa, C., Bamutaze, Y., Ayesiga, G. et al. (2017). Assessing the Performance of WRF Model in Simulating Rainfall over Western Uganda. Journal of Climatology \& Weather Forecasting, 5, 1-9.

Mugume, I., Basalirwa, C., Waiswa, D., Reuder, J., Mesquita, M. S., Tao, S., \& Ngailo, T. J. (2016). Comparison of Parametric and Nonparametric Methods for Analyzing the Bias 
of a Numerical Model. Modelling and Simulation in Engineering, 2016, Article ID: 7530759. https://doi.org/10.1155/2016/7530759

Ntwali, D., Ogwang, B. A., \& Ongoma, V. (2016). The Impacts of Topography on Spatial and Temporal Rainfall Distribution over Rwanda Based on WRF Model. Atmospheric and Climate Sciences, 6, 145-157. https://doi.org/10.4236/acs.2016.62013

Schaefer, J. T. (1990). The Critical Success Index as an Indicator of Warning Skill. Weather and Forecasting, 5, 570-575. https://doi.org/10.1175/1520-0434(1990)005<0570:TCSIAA >2.0.CO;2

Skamarock, W. C., Klemp, J. B., Dudhi, J., Gill, D. O., Barker, D. M., Duda, M. G., Powers, J. G. et al. (2008). A Description of the Advanced Research WRF Version 3 (p. 113). NCAR Technical Note, (June).

Sun, X., Xie, L., Semazzi, F. H. M., \& Liu, B. (2014). A Numerical Investigation of the Precipitation over Lake Victoria Basin Using a Coupled Atmosphere-Lake Limited-Area Model. Advances in Meteorology, 2014, Article ID: 960924. https://doi.org/10.1155/2014/960924

Warner, T. T. (2011). Quality Assurance in Atmospheric Modeling. American Meteorological Society, 92, 1601-1610. https://doi.org/10.1175/BAMS-D-11-00054.1

Willmott, C. J., Ackleson, S. G., Davis, R. E., Feddema, J. J., Klink, K. M., Legates, D. R., Rowe, C. M. et al. (1985). Statistics for the Evaluation and Comparison of Models. Journal of Geophysical Research, 90, 8995-9005.

https://doi.org/10.1029/JC090iC05p08995 